\title{
RESEARCH
}

Open Access

\section{Prevalence and risk factors of HIV infection among people who inject drugs in Cambodia: findings from a national survey}

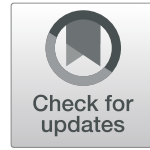

\author{
Gitau Mburu ${ }^{1,2}$, Pheak Chhoun ${ }^{3}$, Navy Chann ${ }^{4}$, Sovannary Tuot ${ }^{3}$, Phalkun Mun ${ }^{4}$ and Siyan $\mathrm{Yi}^{3,5,6^{*}}$ (D)
}

\begin{abstract}
Background: Globally, people who inject drugs (PWID) continue to be among the most vulnerable populations to acquire infection of human immunodeficiency virus (HIV). The most recent national survey found that nearly a quarter of PWID in Cambodia were infected with HIV in 2012. The aim of this study is to estimate the current prevalence of and factors associated with HIV infection among PWID in Cambodia.
\end{abstract}

Methods: This national integrated biological and behavioral survey was conducted from June to December 2017. Participants were recruited from the capital city and 11 major provinces using the respondent driven sampling method. Face-to-face interviews were conducted using a structured questionnaire, and blood samples were collected for HIV, syphilis, and hepatitis C virus ( $\mathrm{HCV}$ ) testing. Multiple logistic regression analysis was conducted to identify risk factors for HIV infection. All analyses were estimated with sampling weights that corrected for nonresponse and sample design.

Results: A total of 310 PWID participated in the study, and the mean age was 31.8 years $(S D=7.8)$. The prevalence of HIV was $15.2 \%$. More than half (57.4\%) of the HIV-positive participants were co-infected with HCV, and $44.7 \%$ were not aware of their HIV status prior to this study. After adjustment for other covariates, HIV infection remained positively associated with being female ( $A O R=1.88,95 \% \mathrm{Cl}=1.03-4.04)$, being in the older age group of $\geq 35$ ( $A O R=2.99,95 \% \mathrm{Cl} 1.33-9.22)$, being widowed, divorced or separated ( $A O R=2.57,95 \% \mathrm{Cl}=1.04-6.67)$, living on the streets ( $A O R=2.86,95 \% \mathrm{Cl} 1.24-4.37$ ), and HCV infection ( $\mathrm{AOR}=3.89,95 \% \mathrm{Cl} 1.86-1.15)$. The HIV infection remained negatively associated with having higher level of formal education of $\geq 10$ years ( $\mathrm{OOR}=0.44,95 \% \mathrm{Cl} 0.13-0.83$ ) and higher average income of $\geq U S \$ 200$ per month ( $A O R=0.20,95 \% \mathrm{Cl}=0.05-0.74$ ).

Conclusions: The prevalence of HIV among PWID in Cambodia remains high, but is reducing compared with the 24.8\% reported in the 2012 national survey. Findings from this study provide critical information for tailoring interventions based on identified vulnerabilities and risk factors for HIV. Our findings underline the importance of socio-structural factors in HIV epidemiology among PWID in Cambodia, which require mitigation.

Keywords: HIV risk, Injecting drug use, Harm reduction, National survey, Prevalence, Cambodia

\footnotetext{
* Correspondence: siyan@doctor.com

${ }^{3}$ KHANA Center for Population Health Research, Phnom Penh, Cambodia

${ }^{5}$ Center for Global Health Research, Touro University California, Vallejo, USA

Full list of author information is available at the end of the article
}

(c) The Author(s). 2019 Open Access This article is distributed under the terms of the Creative Commons Attribution 4.0 International License (http://creativecommons.org/licenses/by/4.0/), which permits unrestricted use, distribution, and reproduction in any medium, provided you give appropriate credit to the original author(s) and the source, provide a link to the Creative Commons license, and indicate if changes were made. The Creative Commons Public Domain Dedication waiver (http://creativecommons.org/publicdomain/zero/1.0/) applies to the data made available in this article, unless otherwise stated. 


\section{Background}

In Cambodia, people who inject drugs (PWID) are a priority group for HIV prevention, as they comprise an important key population at risk of human immunodeficiency virus (HIV) infection $[1,2]$. Previous studies in the country have characterized the HIV epidemic among PWID. A national Integrated Biological and Behavioral Survey (IBBS) conducted in 2012 reported that the prevalence of HIV among PWID in Cambodia was 24.8\% [3]. The vast majority of Cambodian PWID are male, reside in urban areas, and mostly inject heroin [3, 4]. Documented risk factors for HIV acquisition among PWID in Cambodia include needle/syringe sharing $[3,5]$.

To respond to the needs of PWID, intensive HIV prevention interventions have been implemented throughout the country as part of the Boosted Continuum of Prevention, Care, and Treatment (B-CoPCT) strategy, which was initiated in $2012[1,2]$. B-CoPCT strategy aims to achieve the "Three Zeros" (i.e. zero new HIV infection, zero discrimination, and zero AIDS-related deaths) by 2020 [2, 6, 7]. B-CoPCT interventions for PWID include needle and syringe exchange programs, condom promotion, peer education, community-based outreach, medically assisted therapy, and peer-led HIV voluntary confidential counseling and testing, which are provided via both governmental and non-governmental organizations (NGOs) [3, 4]. As a result of these efforts, Cambodia has made tremendous progress in reducing HIV prevalence and incidence [2], and is one of the few countries in the world that are close to achieving the 90-90-90 global targets by 2020 [8].

As the HIV epidemic abates, focus has shifted to an HIV case detection model that ensures linkage to care and treatment for all detected infections [2, 4]. As in other settings [9-11], there is an emerging consensus that eliminating the HIV epidemic in Cambodia requires granulating the HIV risk factors and addressing them at the local level, for each of the key populations at risk of HIV [1, 4]. Therefore, a critical part of ongoing HIV prevention is understanding emerging risk profiles and ensuring that HIV programs respond to different strata of PWID. It is in this context that the government has committed to strengthen the strategic information related to PWID, including separating them from the general category of people who use drugs (PWUD) [1]. This separation is essential to ensure that provision of clean needles, syringes, and medical assisted therapy is optimized among people who specifically inject drugs as recommended by the World Health Organization [12]. Lumping injectors and non-injectors may fail to distinguish varying levels of risk between people who inject and those who consume drugs by other modes [13].

To achieve Cambodia's national HIV prevention goals, routine behavioral surveillance of key populations is routinely conducted to characterize national trends in the epidemic, and strategic information informs the development of effective HIV interventions. This paper focusses on PWID and aims to report: (1) an estimate of HIV prevalence; (2) factors associated with HIV infection; and (3) potential ways in which programs can be adjusted to enhance HIV prevention among this key population in Cambodia.

\section{Methods}

Study design, sites, and participants

A cross-sectional survey was conducted from June to December 2017. Data were collected from participants in the capital city of Phnom Penh and 11 major provinces, which were purposively selected following a feasibility assessment. These 12 study sites contained 21 operational districts with high-burden of drug use and HIV. PWID were defined as people who have injected any type of illicit drugs, as specified by the Cambodian Law on Control of Drugs, in the past 12 months [14].

\section{Inclusion and exclusion criteria}

Individuals would be included in the study if they: (1) were 18 years or older; (2) presented a valid study recruitment coupon; (3) injected any illicit drug in the past 12 months; and (4) were willing and able to provide informed consent for study participation. To prevent multiple participation, participants were excluded if they had already participated in this survey elsewhere in the country.

\section{Sample size calculation}

The sample size calculation was based on an estimated PWID population size of 1300 [3] and an assumption of a 20\% decrease in the HIV prevalence since the 2012 IBBS. Using a margin of error of $1.5 \%$, a confidence interval of $95 \%$, a $90 \%$ response rate and a design effect of 1.5 , the minimum sample size required for this study was 290. Roughly $25.0 \%$ of the estimated 1068 PWID in Phnom Penh in 2016 [15] were recruited, assuming that, based on programs reports, there would be no PWID in sites outside the capital city. However, PWID found in any sites would be included in the study.

\section{Recruitment}

The Respondent Driven Sampling (RDS) method was used to recruit study participants, and the Strengthening the Reporting of Observational Studies in Epidemiology for RDS Studies (STROBE-RDS) statement was followed [16]. RDS is a network-based method to recruit participants from hidden populations such as people who use drugs, commercial sex workers, and men who have sex with men [17], and is frequently used to estimate characteristics of hard-to-reach groups, such as the HIV prevalence [16]. 
The RDS was implemented in five stages. First, four eligible PWID who were well-connected to other PWID in each location were selected as seeds to recruit other PWID in their network. Second, each seed was given a Personal Identification Number (PIN) and enrolled as a participant. Third, each seed received three coupons and was asked to refer three additional PWID. Seeds received US $\$ 2$ for each successful recruit, while each recruit received a gift costing approximately US $\$ 5$ to compensate for their time and transport. Each seed was expected to extend up to 3 to 6 "recruitment waves" in each site. If the initial seeds did not recruit participants or if enrollment has been halted because all recruitment chains have "dried up" (i.e. stopped recruiting), additional seeds would be selected based on the above criteria. All recruits were provided the same opportunity as seeds to recruit other PWID.

\section{Data collection training}

A data collection team was provided with a three-day training on the study protocol and the process of data collection to ensure that the team members were thoroughly familiar with the study. The training workshop covered skills such as interview techniques as well as participant confidentiality and privacy projection. It also provided the team with an opportunity to practice questionnaire administration and pretest the tools. Regular daily review sessions with interviewers were conducted during the data collection to review progress and communicate and resolve any issues encountered.

\section{Data collection procedures}

\section{Biological data collection}

HIV and syphilis screening was conducted with capillary blood by a laboratory technician using SD Bioline HIV/ Syphilis Duo Test (Standard Diagnostic Inc., Korea). A non HIV-reactive result establishes that an individual is not HIV-infected. HIV reactive results were confirmed using HIV 1/2 STAT-PAK ${ }^{\circ}$ Assay (Chembio Diagnostic 127 Systems Inc., New York). HCV antibody testing was performed using capillary blood with HCV Oraquick (OraSure Technologies, Inc., Bethlehem). Participants received their results verbally in a post-test counseling session after the interview. All newly identified HIV and syphilis cases were linked to a local NGO in the area for further management according to national guidelines. HCV-positive cases were referred to Médecins Sans Frontières for care and treatment support.

\section{Questionnaire development and measures}

Standardized and validated tools were adapted from previous studies among HIV key populations in Cambodia and the most recent Cambodia Demographic and Health Survey $[3,18-21]$. The structured questionnaire was initially developed in English and then translated into Khmer, the national language of Cambodia. It was then back-translated into English by another translator to ensure that the "content and spirit" of every original item were maintained. A consultative meeting was held with representatives of key stakeholders working on HIV and harm reduction and community people to review the study protocol and tools. A pilot study was conducted with 10 PWID in Phnom Penh, who were later excluded from the main study.

Socio-demographic characteristics included type of community (urban or rural), age (continuous), gender (male or female), years of formal education attained (continuous), average income in the past six months (continuous), living situation (homeless, with family, own dwelling, with friends, or other), employment status (unemployed, entertainment worker, office worker, laborer/farmer, or other), ethnicity (Khmer, Vietnamese, or other), and current marital status (married, never married, or widowed/divorced/separated).

Regarding drug use, we collected information on types of illicit drugs and frequency of use in the past three months. These include the use of drugs (yes or no) and type of drugs used (heroin, Yama/methamphetamine, ecstasy or inhalants) in the last three months. To assess risky injecting behaviors, PWID were asked about consistent use of new needles/syringes and sharing of needles with other PWID. Alcohol use was assessed by asking participants if they consumed alcohol $\geq 3$ times per week and whether they binge drank $\geq 3$ times per week. To measure HIV risks, participants were asked about their sexual behaviors in the past three months including number of partners and condom use with commercial (defined as a partner with whom the participant had sex in exchange for money or goods) and noncommercial partners in the past three months. We also collected information regarding STI symptoms and exposure to community-based HIV, harm reduction, and other related services in the past six months.

\section{Statistical analyses}

All analyses were estimated with sampling weights that corrected for nonresponse and sample design [22]. The prevalence of HIV was calculated by dividing the total number of HIV-positive participants with the total number of participants tested. Characteristics and behavioral variables of HIV-positive participants were compared to those of HIV-negative participants using Chi-square test (or Fisher's exact test for an expected cell value of $\leq 5$ ) for categorical variables and Student's $t$-test or MannWhitney $U$ test for continuous variables. Age, level of education, and income were transformed into categorical variables. To identify risk factors for HIV infection, variables associated with HIV infection at a significance level of $p<0.05$ in bivariate analyses were simultaneously 
included in a multiple logistic regression model. Age, gender, level of education, and income were included in the model regardless of the significance level in bivariate analyses. Backward stepwise selection method was used to eliminate variables with the highest $p$-value one-byone from the model. Adjusted odds ratios (AOR) and 95\% confidence intervals (CI) were calculated. STATA Version 12.0 for Windows (Stata Corp, TX, USA) was used for the analyses.

\section{Results}

\section{Prevalence of HIV}

This study included 310 PWID with a mean age of 31.8 years $(\mathrm{SD}=7.8)$. Forty-seven participants $(15.2 \%)$ tested positive for $\mathrm{HIV}(95 \% \mathrm{CI}=4.6-7.1 \%)$. More than half (57.4\%) of the HIV-positive individuals were co-infected with HCV. The majority of the HIV-positive cases (95.7\%) were found in Phnom Penh, and 44.7\% were not aware of their HIV status prior to the study. Of the 26 cases who were aware of their HIV status, $84.0 \%$ were on ART.

\section{Socio-demographic characteristics}

The majority (70.3\%) of the participants lived in Phnom Penh. As shown in Tables 1, 91.6\% resided in urban areas; $73.2 \%$ were male; $40.6 \%$ were married; and $56.1 \%$ had attained only primary education. While 39.4\% reported living with their family or relatives, $27.1 \%$ were living on the streets. The most common job was a laborer or farmer $(37.4 \%)$, and $12.6 \%$ were unemployed. The majority $(78.6 \%)$ reported an average monthly income in the past six months of $<$ US $\$ 200$. A significantly higher proportion of HIV-positive participants were in the age group of $\geq 35$ (57.4\% vs. $35.5 \%, p<0.001)$; widowed, divorced, or separated $(34.0 \%$ vs. $16.3 \%, p=$ 0.008 ) ; had completed only primary formal education (72.3\% vs. $53.2 \%, p=0.008)$; lived on the streets $(44.7 \%$ vs. $24.0 \%, p=0.003)$; and had an average monthly income of $<\mathrm{US} \$ 100$ (46.8\% vs. $34.4 \%, p=0.009$ ) compared to the HIV-negative group.

\section{Substance use}

Table 2 shows that heroin was the most commonly used drug in the past three months (60.4\%), followed by Yama/ice (common name for methamphetamine in Cambodia) (24.2\%). About two-thirds (64.8\%) reported that they always used new syringes/needles for drug injection in the past three months, while the remaining $23.5 \%$ reported using needles or syringes that had been used by someone else over the same period. Alcohol use was also common with $29.7 \%$ reporting alcohol drinking at least three times per week; of these, $47.4 \%$ reported binge drinking (drinking at least five units of alcoholic drinks on a typical day) at least three days per week in the past three months. A significantly lower proportion of HIV-positive participants reported alcohol drinking $\geq 3$ times per week in the past three months $(8.5 \%$ vs. $33.5 \%, p=0.001)$.

\section{Sexual behaviors}

As shown in Tables 3, 17.5\% reported always using condoms, while $45.1 \%$ reported having sex when a partner was intoxicated in the past three months. Of those who reported having sex with partners not in exchange for money or gifts $(n=117), 8.5 \%$ reported always using condoms with the non-commercial partners in the past three months. Of the total respondents, $22.6 \%$ reported having sex in exchange for money or gifts in the past three months; of whom, $27.3 \%$ reported always using condoms with the commercial partners in the past three months. No significant difference was found in comparison of sexual behaviors in HIV-positive and HIV-negative group.

\section{Hepatitis C and STIs}

As shown in Tables 4, 28.1\% of the participants were tested positive for $\mathrm{HCV}$ and $5.2 \%$ for syphilis, and $28.2 \%$ reported having had at least one STI symptom in the past 12 months. The most commonly reported symptoms included abnormal urethral discharge (65.9\%), followed by swelling around the genital area $(26.1 \%)$ and having cuts or ulcerations around the genital area (25.0\%). Compared to HIV-negative group, a significantly higher proportion of HIV-positive participants were tested positive for $\mathrm{HCV}$ (57.4\% vs. $22.8 \%, p<0.001)$.

\section{Access to community-based HIV services}

Table 5 shows that $68.4 \%$ of the study participants reported having received some form of community-based HIV services in the past six months. The services included condom and lubricant distribution (69.9\%), HIV testing (60.8\%), HIV education (47.9\%), needle and syringe distribution (49.0\%), methadone maintenance therapy (41.9\%), drop-in services $(21.7 \%)$, and HCV testing (20.3\%). The proportion of participants who reported having received overall community-based HIV services $(80.9 \%$ vs. $66.2 \%$, $p=0.04)$ and methadone maintenance therapy $(72.3 \% \mathrm{vs.}$ $36.9 \%, p<0.001$ ) in the past six months was significantly higher among HIV-positive participants compared to that among HIV-negative group.

\section{Factors associated with HIV infection}

Factors associated with HIV infection among PWID in this study are shown in Table 6. After adjustment for other covariates, HIV infection remained positively associated with being female (AOR $=1.88,95 \% \mathrm{CI}=1.03-$ 4.04 ), being in the older age group of $\geq 35$ ( $\mathrm{AOR}=2.99$, 95\% CI 1.33-9.22), being widowed, divorced or separated $(\mathrm{AOR}=2.57,95 \% \mathrm{CI}=1.04-6.67)$, living on the 
Table 1 Socio-demographic characteristics of HIV-positive and HIV-negative PWID

\begin{tabular}{|c|c|c|c|c|}
\hline & \multirow{3}{*}{$\begin{array}{l}\text { Total } \\
(n=310) \\
n(\%)\end{array}$} & \multicolumn{3}{|l|}{ HIV test result } \\
\hline & & \multirow{2}{*}{$\begin{array}{l}\text { Positive }(n=47) \\
n(\%)\end{array}$} & \multicolumn{2}{|c|}{ Negative $(n=263)$} \\
\hline & & & $n(\%)$ & $P$-value \\
\hline Living in an urban community & $284(91.6)$ & $46(97.9)$ & $238(90.5)$ & 0.15 \\
\hline Female gender & $83(26.8)$ & $18(38.3)$ & $65(24.7)$ & 0.07 \\
\hline \multicolumn{4}{|l|}{ Age group } & 0.001 \\
\hline $18-24$ & $59(19.1)$ & $1(2.1)$ & $58(22.1)$ & \\
\hline $25-34$ & $130(42.1)$ & $19(40.4)$ & $111(42.4)$ & \\
\hline$\geq 35$ & $120(38.8)$ & $27(57.4)$ & $93(35.5)$ & \\
\hline \multicolumn{4}{|l|}{ Ethnicity } & 0.23 \\
\hline Khmer & $244(79.0)$ & $34(72.3)$ & $210(80.2)$ & \\
\hline Vietnam & $65(21.0)$ & $13(27.7)$ & $52(19.8)$ & \\
\hline \multicolumn{4}{|l|}{ Current marital status } & 0.008 \\
\hline Never married & $125(40.3)$ & $12(25.5)$ & $113(43.0)$ & \\
\hline Married & $126(40.6)$ & $19(40.4)$ & $107(40.7)$ & \\
\hline Widowed/divorced/separated & $59(19.0)$ & $16(34.0)$ & $43(16.3)$ & \\
\hline \multicolumn{4}{|l|}{ Level of formal education completed } & 0.03 \\
\hline Primary (0-6 years) & $174(56.1)$ & $34(72.3)$ & $140(53.2)$ & \\
\hline Secondary school (7-9years) & $75(24.2)$ & $9(19.1)$ & $66(25.1)$ & \\
\hline High school or higher ( $\geq 10$ years) & $61(19.7)$ & $4(8.5)$ & $57(21.7)$ & \\
\hline \multicolumn{4}{|l|}{ Living arrangement } & 0.003 \\
\hline In the street (homeless) & $84(27.1)$ & $21(44.7)$ & $63(24.0)$ & \\
\hline With family or relatives & $122(39.4)$ & $11(23.4)$ & $111(42.2)$ & \\
\hline In own dwelling & $60(19.4)$ & $5(10.6)$ & $55(20.9)$ & \\
\hline With friends & $15(4.8)$ & $5(10.6)$ & $10(3.8)$ & \\
\hline Other & $29(9.4)$ & $5(10.6)$ & $24(9.1)$ & \\
\hline \multicolumn{4}{|l|}{ Main occupation } & 0.74 \\
\hline Unemployed & $39(12.6)$ & $5(10.6)$ & $34(12.9)$ & \\
\hline Entertainment worker & $32(10.3)$ & $3(6.4)$ & $29(11.0)$ & \\
\hline Office worker & $79(25.5)$ & $15(31.9)$ & $64(24.3)$ & \\
\hline Laborer/farmer & $116(37.4)$ & $17(36.2)$ & 99 (37.6) & \\
\hline Other & $44(14.2)$ & $7(14.9)$ & $37(14.1)$ & \\
\hline \multicolumn{4}{|c|}{ Average monthly income in the past 6 months (US\$) } & 0.009 \\
\hline$<100$ & $112(36.2)$ & $22(46.8)$ & $90(34.4)$ & \\
\hline 100-199 & $131(42.4)$ & $22(46.8)$ & 109 (41.6) & \\
\hline$\geq 200$ & $66(21.4)$ & $3(6.4)$ & $63(24.0)$ & \\
\hline
\end{tabular}

Abbreviations: HIV human immunodeficiency virus, PWID people who inject drugs *Chi-square (or Fisher's exact test when a cell count was smaller than 5) was used

streets $(\mathrm{AOR}=2.86,95 \% \mathrm{CI} 1.24-4.37)$, and $\mathrm{HCV}$ infection $(\mathrm{AOR}=3.89,95 \% \mathrm{CI} 1.86-1.15)$. The HIV infection remained negatively associated with having higher level of formal education of $\geq 10$ years $(\mathrm{AOR}=0.44,95 \% \mathrm{CI}$ $0.13-0.83)$ and higher average income in the past six months of $\geq$ US\$200 per month $(\mathrm{AOR}=0.20,95 \% \mathrm{CI}=$ 0.05-0.74).

\section{Discussion}

A previous national IBBS conducted in year 2012 among PWID found an HIV prevalence of $24.8 \%$ [3, 5]. This 2017 IBBS demonstrates a shift in this prevalence showing that the current prevalence had reduced to $15.2 \%$. At the most basic level, this new prevalence is still about 25 times higher than the estimated $0.6 \%$ among the general 
Table 2 Substance use among HIV-positive and HIV-negative PWID

\begin{tabular}{|c|c|c|c|c|}
\hline & \multirow{3}{*}{$\begin{array}{l}\text { Total } \\
(n=310) \\
n(\%)\end{array}$} & \multicolumn{3}{|c|}{ HIV test result } \\
\hline & & \multirow{2}{*}{$\begin{array}{l}\text { Positive } \\
(n=47) \\
n(\%)\end{array}$} & \multicolumn{2}{|l|}{$\begin{array}{l}\text { Negative } \\
(n=263)\end{array}$} \\
\hline & & & $\overline{n(\%)}$ & $P$-value ${ }^{*}$ \\
\hline Used any drugs in the past 3 months & $271(88.0)$ & $43(91.5)$ & $228(87.4)$ & 0.63 \\
\hline \multicolumn{5}{|l|}{ Type of drugs most commonly used in the past 3 months } \\
\hline Heroin & $165(60.4)$ & $29(67.4)$ & $136(59.1)$ & 0.06 \\
\hline Yama/ice (methamphetamine) & $66(24.2)$ & $10(23.3)$ & $56(24.3)$ & 0.88 \\
\hline Ecstasy & $11(4.0)$ & $0(0.0)$ & $11(4.8)$ & 0.22 \\
\hline Inhalants & $5(1.8)$ & $0(0.0)$ & $5(2.2)$ & 1.00 \\
\hline Always used new syringes/needles & $118(64.8)$ & $16(64.0)$ & $102(65.0)$ & 0.93 \\
\hline Used needles/syringes used by someone else in the past 3 months & $43(23.5)$ & $4(16.0)$ & $39(24.7)$ & 0.38 \\
\hline Alcohol drinking $\geq 3$ times per week & $92(29.7)$ & $4(8.5)$ & $88(33.5)$ & 0.001 \\
\hline Binge drinking $\geq 3$ times per week $(n=190)$ & $90(47.4)$ & $6(35.3)$ & $84(48.6)$ & 0.30 \\
\hline
\end{tabular}

HIV human immunodeficiency virus, IQR interquartile range, PWID people who inject drugs

${ }^{*}$ Chi-square (or Fisher's exact test when a cell count was smaller than 5) was used for categorical variables and Mann-Whitney $U$ test for continuous variables

adult population aged 15-45 in 2016 [23], and suggests the need to continue focussing on this population, alongside other key populations. Furthermore, our results show that $57.4 \%$ of HIV-infected PWID were co-infected with $\mathrm{HCV}$. This study has also identified a number of risk factors of HIV infection including female gender, older age, low level of formal education, low income, homelessness, being widowed/divorced/separated, and having $\mathrm{HCV}$ infection.

The finding that being female almost doubled the odds of HIV infection is in keeping with previous studies from other global contexts showing that women are more vulnerable to HIV [24, 25]. Female gender was also identified as a predictor of HIV infection in the 2012 IBBS in Cambodia that included both PWUD and PWID [3, 5]. While this vulnerability could be due to injection risks, it is possible that this risk is overlaid with sexual risks, such as multiple sexual partners and unprotected sex, as is the case in other contexts [26, 27]. In Cambodia, a better understanding of the profiles of female PWID, including whether they are engaged in sex work to cater for their drug use, and whether their partners inject drugs, could provide further information on risk profiles and assist in HIV prevention programming.

The finding of older age being associated with higher prevalence is similar to findings among other key populations in Cambodia [7, 28]. It is plausible that, as PWID continue to inject, they have more opportunities to acquire HIV [29]. Older age and longer duration of drug use was also identified as a predictor of HIV infection among PWUD and PWID in the 2012 IBBS in Cambodia [3, 5].

Our results show that being homeless was associated with HIV infection. Other studies have shown that homelessness and mobile lifestyles are predictive of both the likelihood to inject [30], as well as poor uptake of harm reduction interventions among PWID [31]. Even in high resource-settings such as Canada and Australia,

Table 3 Sexual behaviors and perceived HIV risk among HIV-positive and HIV-negative PWID

\begin{tabular}{|c|c|c|c|c|}
\hline & \multirow{3}{*}{$\begin{array}{l}\text { Total } \\
(n=310) \\
n(\%)\end{array}$} & \multicolumn{3}{|l|}{ HIV test result } \\
\hline & & \multirow{2}{*}{$\begin{array}{l}\text { Positive }(n=47) \\
n(\%)\end{array}$} & \multicolumn{2}{|c|}{ Negative $(n=263)$} \\
\hline & & & $n(\%)$ & $P$-value \\
\hline Median number of sex partners (IQR) & $1.0(0.0-2.0)$ & $1.0(0.0-1.0)$ & $1.0(0.0-2.0)$ & 0.50 \\
\hline Always used condom with any partner & $34(17.5)$ & $6(21.4)$ & $28(16.9)$ & 0.56 \\
\hline Had sex when a partner was intoxicated & $87(45.1)$ & $9(32.1)$ & $78(47.3)$ & 0.14 \\
\hline Had sex with partners not in exchange for money or gift & $117(60.3)$ & $19(67.9)$ & $98(59.0)$ & 0.38 \\
\hline Always used condom with partners not in exchange for money or gift & $10(8.5)$ & $3(15.8)$ & $7(7.1)$ & 0.21 \\
\hline Had sex in exchange for money or gifts & $44(22.6)$ & $7(25.0)$ & $37(22.2)$ & 0.74 \\
\hline Always used condom with partners in exchange for money or gift & $12(27.3)$ & $2(28.6)$ & $10(27.0)$ & 0.93 \\
\hline
\end{tabular}

HIV human immunodeficiency virus, IQR interquartile range, $P$ WID people who inject drugs

${ }^{*}$ Chi-square (or Fisher's exact test when a cell count was smaller than 5) was used for categorical variables and Mann-Whitney $U$ test for continuous variables 
Table 4 Comparisons of STI symptoms among HIV-positive and HIV-negative PWID

\begin{tabular}{|c|c|c|c|c|}
\hline & \multirow{3}{*}{$\begin{array}{l}\text { Total } \\
(n= \\
310) \\
n(\%)\end{array}$} & \multicolumn{3}{|l|}{ HIV test result } \\
\hline & & \multirow{2}{*}{$\begin{array}{l}\text { Positive }(n=47) \\
n(\%)\end{array}$} & \multicolumn{2}{|c|}{ Negative $(n=263)$} \\
\hline & & & $\overline{n(\%)}$ & $P$-value ${ }^{*}$ \\
\hline Tested positive for hepatitis $C$ & $87(28.1)$ & $27(57.4)$ & $60(22.8)$ & $<0.001$ \\
\hline Tested positive for syphilis & $16(5.2)$ & $3(6.4)$ & $13(4.9)$ & 0.72 \\
\hline Had any STI symptoms & $87(28.2)$ & $12(25.5)$ & $75(28.6)$ & 0.66 \\
\hline Cuts or sores around the genitals & $22(25.0)$ & $1(8.3)$ & $21(27.6)$ & 0.28 \\
\hline Swelling around the genitals & $23(26.1)$ & $1(8.3)$ & $22(28.9)$ & 0.17 \\
\hline Abnormal urethral discharge & $58(65.9)$ & $9(75.0)$ & $49(64.5)$ & 0.74 \\
\hline Symptoms around the anus & $12(13.6)$ & $2(16.7)$ & $10(13.2)$ & 0.67 \\
\hline Symptoms in the mouth or throat & $10(11.4)$ & $0(0.0)$ & $10(13.2)$ & 0.35 \\
\hline Received treatment for most recent STI & $69(79.3)$ & $11(91.7)$ & $58(77.3)$ & 0.26 \\
\hline
\end{tabular}

HIV human immunodeficiency virus, PWID people who inject drugs, STI sexually transmitted infections

*Chi-square or Fisher's exact test was used as appropriate

injecting drugs is frequently associated with both unemployment and homelessness [30, 32]. In turn, homelessness is likely to increase the risk of HIV infection $[33,34]$ by acting as a structural barrier to accessing harm reduction interventions $[31,35]$. Homelessness encourages sharing and other risk taking among PWID [35]. On a practical level, this finding provides a useful way in which to categorize profiles of HIV risk among PWID and suggests that outreach to homeless PWID will be essential in HIV case finding and prevention. This is particularly important given that $27.1 \%$ of the sampled PWID were living on the streets.

Because unsafe injection is a common risk factor for parenteral acquisition of both HIV and HCV [36, 37], it is not surprising that a significant proportion of PWID in this study were co-infected with both of these viral infections. Among adults living with HIV in Cambodia, $\mathrm{HIV} / \mathrm{HCV}$ co-infection rates between 5.3 and $10.5 \%$ have been reported [38-40]. However, these previous studies included a limited number of PWID, as compared to the heterosexual general population. As such, the higher prevalence of co-infection in this IBBS can be explained by the fact that our sample was exclusively composed of PWID.

In our study, having completed at least high school level of formal education almost halved the odds of having HIV. This finding is consistent with previous studies in Cambodia that have demonstrated that higher levels of education are protective against HIV infection [7, 41]. The finding that lower income is predictive of HIV infection could be related to the impact of structural economics on injection risks. Economic considerations and being in socially deprived situations may indirectly influence risk taking behaviors such as needle sharing [42]. This might explain why widowed, divorced or separated PWID had a higher risk of HIV, although this may also result from sexual acquisition of HIV from their partners, whose HIV status was not enquired or documented.

\section{Policy implications}

Our findings show the need to focus on macro-social and structural factors that determine HIV acquisition

Table 5 Access to community-based HIV services among HIV-positive and HIV-negative PWID

\begin{tabular}{|c|c|c|c|c|}
\hline & \multirow{3}{*}{$\begin{array}{l}\text { Total } \\
(n=310) \\
n(\%)\end{array}$} & \multicolumn{3}{|l|}{ HIV test result } \\
\hline & & \multirow{2}{*}{$\begin{array}{l}\text { Positive }(n=47) \\
n(\%)\end{array}$} & \multicolumn{2}{|c|}{ Negative $(n=263)$} \\
\hline & & & $n(\%)$ & $P$-value \\
\hline Received community-based HIV services & $212(68.4)$ & $38(80.9)$ & $174(66.2)$ & 0.04 \\
\hline HIV education services & $68(47.9)$ & $15(57.7)$ & $53(45.7)$ & 0.27 \\
\hline Condom and lube distribution & $100(69.9)$ & $22(84.6)$ & $78(66.7)$ & 0.10 \\
\hline Needle and syringe distribution & $70(49.0)$ & $15(57.7)$ & $55(47.0)$ & 0.32 \\
\hline HIV/STI testing services & $87(60.8)$ & $16(61.5)$ & $71(60.7)$ & 0.94 \\
\hline Hepatitis $C$ testing services & $63(20.3)$ & $15(31.9)$ & $48(18.3)$ & 0.03 \\
\hline Methadone maintenance therapy & $130(41.9)$ & $34(72.3)$ & $96(36.5)$ & $<0.001$ \\
\hline
\end{tabular}

HCV hepatitis $C$ virus, HIV human immunodeficiency virus, PWID people who inject drugs, STI sexually transmitted infections

${ }^{*}$ Chi-square or Fisher's exact test was used as appropriate 
Table 6 Factors associated with HIV infection among PWID in multivariate logistic regression model

\begin{tabular}{|c|c|}
\hline Variables in the final model* & AOR $(95 \% \mathrm{Cl})$ \\
\hline \multicolumn{2}{|l|}{ Gender } \\
\hline Male & Reference \\
\hline Female & $1.88(1.03-4.04)$ \\
\hline \multicolumn{2}{|l|}{ Age group } \\
\hline$<25$ & Reference \\
\hline $25-34$ & $1.44(0.66-4.47)$ \\
\hline$\geq 35$ & $2.99(1.33-9.22)$ \\
\hline \multicolumn{2}{|l|}{ Current marital status } \\
\hline Never married & Reference \\
\hline Married & $0.96(0.39-2.34)$ \\
\hline Widowed/divorced/separated & $2.57(1.04-6.67)$ \\
\hline \multicolumn{2}{|l|}{ Level of formal education completed } \\
\hline Primary (0-6 years) & Reference \\
\hline Secondary school (7-9years) & $0.85(0.35-2.05)$ \\
\hline High school or higher ( $\geq 10$ years) & $0.44(0.13-0.83)$ \\
\hline \multicolumn{2}{|c|}{ Average monthly income in the past 6 months (US\$) } \\
\hline$<100$ & Reference \\
\hline $100-199$ & $0.94(0.45-1.94)$ \\
\hline$\geq 200$ & $0.20(0.05-0.74)$ \\
\hline \multicolumn{2}{|l|}{ Living arrangement } \\
\hline With family/relatives & Reference \\
\hline On the streets (homeless) & $2.86(1.24-4.37)$ \\
\hline In own dwelling & $1.19(0.53-7.95)$ \\
\hline With friends & $1.48(0.62-9.74)$ \\
\hline \multicolumn{2}{|l|}{ HCV test result } \\
\hline Negative & Reference \\
\hline Positive & $3.89(1.86-8.15)$ \\
\hline
\end{tabular}

$A O R$ adjusted odds ratio, $\mathrm{Cl}$ confidence interval, $H C V$ hepatitis $\mathrm{C}$ virus, $H I V$ human immunodeficiency virus, $P W I D$ people who inject drugs

"Age, gender, marital status, education level, entertainment venue, and variables associated with HIV infection in the bivariate analyses at a level of $p<0.05$ were simultaneously included in the model

including homelessness, gender, and economic power. Therefore, such macro level interventions should be enhanced, alongside the current interventions in B-CoPCT, which tend to emphasize individual- and facility-level determinants including behavior change, provision of needles/syringes and medically assisted therapy, and management of co-morbidities.

Structural factors such as lack of employment and gender inequity mediate HIV risks among PWID by enhancing their vulnerabilities to $\operatorname{HIV}[30,31,43,44]$. Therefore, addressing structural determinants will be essential. Evidence supports our assertions on the importance of macro-level determinants of HIV infection. In a large study of 1633 Canadian PWID, structural factors such as having personal or social support, a regular place to stay, and formal employment opportunities all reduced risky drug injection behaviors [44]. In the United States, microfinance interventions and support with legitimate employment reduced the amounts and frequency of drugs that women used [45]. In Indonesia, females who injected drugs who were financially independent had more control on their drug use and attendant HIV risks [46]. Therefore, proactively combating homelessness, enhancing employment opportunities, and addressing gender-based economic inequity could mitigate the risk of HIV acquisition among PWID in Cambodia. Such approaches need to be explored as a policy priority.

\section{Study limitations}

This study has some limitations. First, the crosssectional study provides a snapshot of prevalence, which does not allow us to examine the temporality of the associations. Second, recruitment bias may exists because this study included 12 provinces with the highest burden of HIV and drug use, leaving out 13 provinces with lower burden of these phenomena, and a significant proportion of PWID was recruited from the capital city. However, our aim in recruiting a large sample from these high-burden sites for this national survey was to ensure the widest possible generalizability while ensuring that the study was feasible. Furthermore, any PWID identified in the provinces was included in the study. Given these complex sample survey data, the statistical methods such as Taylor series approximations should have been performed to adjust the standard errors for the sample design effects. Third, this study utilized selfreporting measures to gather sensitive information on drug use and sexual behaviors, which could have been affected by social desirability bias as is the case in other studies of PWID [47]. Finally, it is possible that the incentive provided to the participants may have affected their genuine motivation to participate, but we anticipate that the impact of the bias is minimal.

\section{Conclusions}

This national survey found that the prevalence of HIV among PWID was $15.2 \%$, which is a reduction from the $24.8 \%$ reported in a similar IBBS in 2012 [3, 5]. Among those currently infected with HIV, $57.4 \%$ were found to be co-infected with HCV. The prevalence of HIV was independently associated with being female, older, being widowed/divorced/separated, low level of formal education, low income, living on the streets, and having HCV infection. Given the current wide coverage of all the comprehensive package of HIV prevention, treatment, and care services in Cambodia [1,2], we suggest that to prevent and control the HIV epidemic in this context, 
intervention programs and messages should be tailored to PWID with the above social demographic profiles, emphasizing on macro-structural interventions. Given that $44.7 \%$ of PWID in this study were not aware of their HIV status prior to the survey, it is important to reach the more hidden PWID through innovative strategies, and RDS method can be an effective approach to reach those who have not been reached by the traditional approaches.

\begin{abstract}
Abbreviations
AIDS: Acquired immune deficiency syndrome; AOR: Adjusted odd ratio; BCOPCT: Boosted Continuum of Prevention, Care, and Treatment; HCV: Hepatitis C virus; HIV: Human immunodeficiency virus; IBBS: Integrated biological and behavioral survey; IQR: Interquartile range; NECHR: National Ethics Committee for Health Research; NGO: Non-governmental organization; PWID: People who inject drugs; PWUD: People who use drugs: RDS: Respondent driven sampling; SD: Standard deviation; STI: Sexually transmitted infections

\section{Acknowledgements}

We thank the National HIV/AIDS Technical Working Group for providing excellence technical inputs and guidance to develop and implement the survey. This study would not have been a success without excellent contribution from data collection teams, community-based organizations, local authorities, and all participants.
\end{abstract}

\section{Disclaimer}

Contents of this paper are the responsibility of the authors and do not reflect the view of the Global Fund, or our respective institutions.

\section{Authors' contributions}

SY, ST, and PM designed the study and developed the study protocol and tools. NC, PC, TS, and PM were responsible for trainings and data collection. SY and GM analyzed data and wrote the manuscript. All authors contributed to the conceptualization of the research questions, interpretation of the results, and manuscript writing. All authors read and approved the final manuscript.

\section{Authors' information}

GM (PhD) is a Researcher at Division of Health Research, Lancaster University, the United Kingdom and a Research Fellow at the Centre for Global Health Policy at the University of Sussex. ST (MA) is Manager and PC (MPH) is Research Fellow at KHANA Center for Population Health Research, Cambodia. PM (MPH) is Chief and NC (MPH) is Deputy Chief of Surveillance Unit, the National Center for HIV/AIDS, Dermatology and STD, Cambodia. SY (PhD) is Senior Research Fellow at Saw Swee Hock School of Public Health, National University of Singapore, Director of KHANA Center for Population Health Research, Cambodia, and Adjunct Professor at Center for Global Health Research, Touro University California, the United States.

\section{Funding}

The National Integrated Biological and Behavioral Survey among people who use and inject drugs 2017 was funded by the Global Fund to Fight AIDS, Tuberculosis and Malaria in Cambodia.

\section{Availability of data and materials}

Data used for this study can be accessed upon request from the Principal Investigator (Dr. Siyan Yi) at ephsyi@nus.edu.sg

\section{Ethics approval and consent to participate}

This study was approved by the National Ethics Committee for Health Research (NECHR) of the Ministry of Health, Cambodia (No. 420 NECHR). A written informed consent was obtained from each participant.

\section{Consent for publication}

Not applicable.

\section{Competing interests}

The authors declare that they have no competing interests.

\section{Author details}

'Division of Health Research, Lancaster University, Lancaster, UK. ${ }^{2}$ Centre for Global Health Policy, University of Sussex, Brighton, UK. ${ }^{3}$ KHANA Center for Population Health Research, Phnom Penh, Cambodia. ${ }^{4}$ National Center for HIV/AIDS, Dermatology and STD, Phnom Penh, Cambodia. ${ }^{5}$ Center for Global Health Research, Touro University California, Vallejo, USA. ${ }^{6}$ Saw Swee Hock School of Public Health, National University of Singapore and National University Health System, Singapore, Singapore.

Received: 9 May 2019 Accepted: 23 September 2019

Published online: 17 October 2019

\section{References}

1. National AIDS Authority. Cambodia Country Progress Report. Monitoring Progress Towards the 2011 UN political declaration on HIV and AIDS. Phnom Penh: National AIDS Authority; 2015

2. Vun MC, Fujita M, Rathavy T, Eang MT, Sopheap S, Sovannarith $S$, et al. Achieving universal access and moving towards elimination of new HIV infections in Cambodia. J Int AIDS Soc. 2014;17:18905. https://doi.org/10. 7448/ias.17.1.18905.

3. Chhea C, Heng S, Tuot S. National Popualtion size estimation, HIV related risk behaviors, HIV prevalence among people who use drugs in Cambodia in 2012. National Authority for Combating Drugs: Phnom Penh; 2014.

4. Mburu G, Ngin C, Tuot S, Chhoun P, Pal K, Yi S. Patterns of HIV testing, drug use, and sexual behaviors in people who use drugs: findings from a community-based outreach program in Phnom Penh. Cambodia Addict Sci Clin Pract. 2017;12(1):27. https://doi.org/10.1186/s13722-017-0094-9.

5. Sopheab H, Chhea C, Tuot S, Muir JA. HIV prevalence, related risk behaviors, and correlates of HIV infection among people who use drugs in Cambodia. BMC Infect Dis. 2018;18(1):562. https://doi.org/10.1186/s12879-018-3472-3.

6. National Center for HIV/AIDS, Dermatology and STD. Standard Operation Procedure (SoP) for Boosted Continuum of Prevention to Care and Treatment for Most at Risk Population in Cambodia. Phnom Penh: National Center for HIV/AIDS, Dermatology and STD; 2013.

7. Weissman A, Ngak S, Srean C, Sansothy N, Mills S, Ferradini L. HIV prevalence and risks associated with HIV infection among transgender individuals in Cambodia. PLoS One. 2016;11(4):e0152906. https://doi.org/10. 1371/journal.pone.0152906.

8. Granich R, Gupta S, Hall I, Aberle-Grasse J, Hader S, Mermin J. Status and methodology of publicly available national HIV care continua and 90-90-90 targets: a systematic review. PLoS Med. 2017;14(4):e1002253. https://doi.org/ 10.1371/journal.pmed.1002253.

9. Levi J, Raymond A, Pozniak A, Vernazza P, Kohler P, Hill A. Can the UNAIDS 90-90-90 target be achieved? A systematic analysis of national HIV treatment cascades. BMJ Glob Health. 2016;1(2):e000010. https://doi.org/10. 1136/bmjgh-2015-000010.

10. Staveteig S, Croft TN, Kampa KT, Head SK. Reaching the 'first 90': gaps in coverage of HIV testing among people living with HIV in 16 African countries. PLoS One. 2017;12(10):e0186316. https://doi.org/10.1371/journal. pone.0186316

11. Risher $\mathrm{K}$, Mayer $\mathrm{KH}$, Beyrer C. HIV treatment cascade in MSM, people who inject drugs, and sex workers. Curr Opin HIV AIDS. 2015;10(6):420-9. https:// doi.org/10.1097/coh.0000000000000200.

12. World Health Organization. Technical guide for countries to set targets for universal access to HIV prevention, treatment and Care for Injecting Drug Users. Geneva: World Health Organization; 2009.

13. Tavitian-Exley I, Vickerman P, Bastos FI, Boily MC. Influence of different drugs on HIV risk in people who inject: systematic review and meta-analysis. Addiction. 2015;110(4):572-84. https://doi.org/10.1111/add.12846.

14. United Nations High Commissioner for Human Rights. Law on control of drugs. Phnom Penh: United Nations High Commissioner for Human Rights; 1996.

15. KHANA. HIV/AIDS flagship annual Progress report to President's emergency plan for AIDS relief (PEPFAR)/United States Agency for International Development (USAID), Cambodia. KHANA: Phnom Penh; 2017.

16. White RG, Hakim AJ, Salganik MJ, Spiller MW, Johnston LG, Kerr L, et al. Strengthening the reporting of observational studies in epidemiology for 
respondent-driven sampling studies:"STROBE-RDS" statement. J Clin Epidemiol. 2015;68(12):1463-71.

17. Heckathorn DD. Respondent-driven sampling: a new approach to the study of hidden populations. Soc Problems. 1997;44(2):174-99.

18. Mun P, Chhim S, Chhoun P, Tuot S, Ly C, Dionisio J, et al. National population size estimation, HIV related risk behaviors, and HIV prevalence among men who have sex with men in Cambodia in 2014. National Center for HIV/AIDS, Dermatology and STD: Phnom Penh; 2016.

19. Mun P, Tuot S, Chhim S, Chhoun P, Ly C, Pal K, et al. Integrated biological and behavioral survey among transgender women in Cambodia. National Center for HIV/AIDS, Dermatology and STD: Phnom Penh, Cambodia; 2016

20. Yi S, Chhoun P, Brant $S$, Kita K, Tuot $S$. The sustainable action against HIV and AIDS in communities (SAHACOM): end-of-project evaluation. KHANA: Phnom Penh; 2014.

21. National Institute of Statistics. Cambodia demographic and health survey 2014. Phnom Penh: National Institute of Statistics; 2015.

22. Bell BA, Onwuegbuzie AJ, Ferron JM, Jiao QG, Hibbard ST, Kromrey JD. Use of design effects and sample weights in complex health survey data: a review of published articles using data from 3 commonly used adolescent health surveys. Am J Public Health. 2012;102(7):1399-405. https://doi.org/10. 2105/ajph.2011.300398.

23. Chhorvann C, Vonthanak S. Estimations and projections of HIV/AIDS in Cambodia 2010-2015. National Center for HIV/AIDS, Dermatology and STD: Phnom Penh; 2011.

24. Eluwa GI, Strathdee SA, Adebayo SB, Ahonsi B, Adebajo SB. A profile on HIV prevalence and risk behaviors among injecting drug users in Nigeria: should we be alarmed? Drug Alcohol Depend. 2013;127(1-3):65-71. https://doi.org/ 10.1016/j.drugalcdep.2012.06.013.

25. Scheibe A, Makapela D, Brown B, dos Santos M, Hariga F, Virk H, et al. HIV prevalence and risk among people who inject drugs in five south African cities. Int J Drug Policy. 2016;30:107-15. https://doi.org/10.1016/j.drugpo. 2016.01.004.

26. Higgs P, Owada K, Hellard M, Power R, Maher L. Gender, culture and harm: an exploratory study of female heroin users of Vietnamese ethnicity. Cult Health Sex. 2008;10(7):681-96. https://doi.org/10.1080/13691050802203838.

27. Evans JL, Hahn JA, Page-Shafer K, Lum PJ, Stein ES, Davidson PJ, et al. Gender differences in sexual and injection risk behavior among active young injection drug users in San Francisco (the UFO study). J Urban Health. 2003;80(1):137-46. https://doi.org/10.1093/jurban/jtg137.

28. Tuot S, Mburu G, Mun P, Chhoun P, Chann N, Prem K, et al. Prevalence and correlates of HIV infection among people who use drugs in Cambodia: a cross-sectional survey using respondent driven sampling method. BMC Infect Dis. 2019 Jun 11;19(1):515. https://doi.org/10.1186/s12879-019-4154-5.

29. Darke $S$. The life of the heroin user: typical beginnings, trajectories and outcomes. New York: Cambridge University Press; 2011.

30. Feng C, DeBeck K, Kerr T, Mathias S, Montaner J, Wood E. Homelessness independently predicts injection drug use initiation among street-involved youth in a Canadian setting. J Adolesc Health. 2013;52(4):499-501. https:// doi.org/10.1016/j.jadohealth.2012.07.011.

31. Whittaker E, Swift W, Roxburgh A, Dietze P, Cogger S, Bruno R, et al. Multiply disadvantaged: health and service utilisation factors faced by homeless injecting drug consumers in Australia. Drug Alcohol Rev. 2015; 34(4):379-87. https://doi.org/10.1111/dar.12257.

32. Crofts N, Louie R, Rosenthal D, Jolley D. The first hit: circumstances surrounding initiation into injecting. Addiction. 1996;91(8):1187-96.

33. Hatzakis A, Sypsa V, Paraskevis D, Nikolopoulos G, Tsiara C, Micha K, et al. Design and baseline findings of a large-scale rapid response to an HIV outbreak in people who inject drugs in Athens. Greece: the ARISTOTLE programme Addiction. 2015;110(9):1453-67. https://doi.org/10.1111/add.12999.

34. Razani N, Mohraz M, Kheirandish P, Malekinejad M, Malekafzali H, Mokri A, et al. HIV risk behavior among injection drug users in Tehran. Iran Addiction. 2007;102(9):1472-82. https://doi.org/10.1111/j.1360-0443.2007.01914.x.

35. Appel PW, Ellison AA, Jansky HK, Oldak R. Barriers to enrollment in drug abuse treatment and suggestions for reducing them: opinions of drug injecting street outreach clients and other system stakeholders. Am J Drug Alcohol Abuse. 2004;30(1):129-53.

36. Aceijas $\mathrm{C}$, Rhodes T. Global estimates of prevalence of HCV infection among injecting drug users. Int J Drug Policy. 2007;18(5):352-8. https://doi.org/10. 1016/j.drugpo.2007.04.004.

37. MacArthur GJ, van Velzen E, Palmateer N, Kimber J, Pharris A, Hope V, et al. Interventions to prevent HIV and hepatitis $C$ in people who inject drugs: a review of reviews to assess evidence of effectiveness. Int J Drug Policy. 2014;25(1):34-52. https://doi.org/10.1016/j.drugpo.2013.07.001.

38. van Griensven J, Phirum L, Choun K, Thai S, De Weggheleire A, Lynen L. Hepatitis B and C co-infection among HIV-infected adults while on antiretroviral treatment: long-term survival, CD4 cell count recovery and antiretroviral toxicity in Cambodia. PLoS One. 2014;9(2):e88552. https://doi. org/10.1371/journal.pone.0088552.

39. De Weggheleire A, An S, De Baetselier I, Soeung P, Keath H, So V, et al. A cross-sectional study of hepatitis $\mathrm{C}$ among people living with HIV in Cambodia: prevalence, risk factors, and potential for targeted screening. PLoS One. 2017;12(8):e0183530. https://doi.org/10.1371/journal.pone. 0183530.

40. Lerolle N, Limsreng S, Fournier-Nicolle I, Ly S, Nouhin J, Guillard B, et al. High frequency of advanced hepatic disease among HIV/HCV co-infected patients in Cambodia: the HEPACAM study (ANRS 12267). J AIDS Clin Res. 2012;3(6)

41. Chhim S, Ngin C, Chhoun P, Tuot S, Ly C, Mun P, et al. HIV prevalence and factors associated with HIV infection among transgender women in Cambodia: results from a national integrated biological and behavioral survey. BMJ Open. 2017;7(8):e015390. https://doi.org/10.1136/bmjopen2016-015390.

42. Rhodes T, Singer M, Bourgois P, Friedman SR, Strathdee SA. The social structural production of HIV risk among injecting drug users. Soc Sci Med. 2005;61(5):1026-44. https://doi.org/10.1016/j.socscimed.2004.12.024.

43. Mburu G, Limmer M, Holland P. HIV risk behaviours among women who inject drugs in coastal Kenya: findings from secondary analysis of qualitative data. Harm Reduct J. 2019;16(1):10. https://doi.org/10.1186/ s12954-019-0281-y.

44. Luchenski S, Ti L, Hayashi K, Dong H, Wood E, Kerr T. Protective factors associated with short-term cessation of injection drug use among a Canadian cohort of people who inject drugs. Drug Alcohol Rev. 2016;35(5): 620-7. https://doi.org/10.1111/dar.12364.

45. Sherman SG, German D, Cheng Y, Marks M, Bailey-Kloche M. The evaluation of the JEWEL project: an innovative economic enhancement and HIV prevention intervention study targeting drug using women involved in prostitution. AIDS Care. 2006;18(1):1-11. https://doi.org/10.1080/ 09540120600838480

46. Lazuardi E, Worth H, Saktiawati AM, Spooner C, Padmawati R, Subronto Y. Boyfriends and injecting: the role of intimate male partners in the life of women who inject drugs in Central Java. Cult Health Sex. 2012;14(5):491503. https://doi.org/10.1080/13691058.2012.671960.

47. Latkin CA, Vlahov D, Anthony JC. Socially desirable responding and selfreported HIV infection risk behaviors among intravenous drug users. Addiction. 1993:88(4):517-26.

\section{Publisher's Note}

Springer Nature remains neutral with regard to jurisdictional claims in published maps and institutional affiliations.

\section{Ready to submit your research? Choose BMC and benefit from:}

- fast, convenient online submission

- thorough peer review by experienced researchers in your field

- rapid publication on acceptance

- support for research data, including large and complex data types

- gold Open Access which fosters wider collaboration and increased citations

- maximum visibility for your research: over $100 \mathrm{M}$ website views per year

At $\mathrm{BMC}$, research is always in progress.

Learn more biomedcentral.com/submissions 